\title{
FLYING FOX TECHNOSPHERE: WISATA DAN PENANGKARAN KELELAWAR DI TAPANGO, SULAWESI BARAT
}

\author{
Julius $^{1)}$, Alvin Hadiwono ${ }^{2)}$ \\ 1)Program Studi S1 Arsitektur, Fakultas Teknik, Universitas Tarumanagara, juliussnjya@yahoo.com \\ 2) Program Studi S2 Arsitektur, Fakultas Teknik, Universitas Tarumanagara, alvinh@ft.untar.ac.id
}

Masuk: 31-05-2021, revisi: 4-08-2021, diterima untuk diterbitkan: dd-mm-2021

\begin{abstract}
Abstrak
Manusia dengan segala kemajuan ilmu pengetahuan dan teknologi, memudahkan segala macam proses dalam berbagai macam kegiatan. Kemudahan yang diberikan ini memiliki dampak yang sangat besar sejak zaman revolusi industri. Namun dengan segala kemudahannya, banyak juga dampak negatif yang dihasilkan dari perkembangan ini hingga mengakibatkan kerusakan ekosistem yang mempengaruhi keseimbangan dalam lingkungan. Salah satu makhluk hidup yang terancam punah akibat perubahan lingkungan, dan tindakan perburuan liar adalah Kalong yang merupakan hewan endemik kepulauan Sulawesi. Untuk mengurangi dan meminimalisir tindakan manusia yang merusak alam, perlu pendekatan dalam penyampaian informasi mengenai pentingnya kehidupan sesama makhluk hidup. Metode yang digunakan adalah pendekatan persepsi yang menggunakan media spasial sebagai bentuk pennyampain informasi. Metode ini diterapkan dalam elemen-elemen pembentuk ruang untuk mencirikan kehidupan Kalong seperti material yang digunakan dalam penyusunan ruang dan tata ruang yang digunakan. Tujuan dari metode ini adalah untuk membuka pemikiran manusia dalam memandang kehidupan makhluk hidup lain serta menyampaikan informasi mengenai peranan makhluk hidup lain dalam ekosistem. Kalong sendiri dipandang oleh masyarakat sebagai hewan pembawa penyakit, sedangkan perannan dari kalong sendiri adalah membantu pelestarian kehidupan hutan. Hasil dari metode ini adalah pembentukan massa bangunan yang mengambil pola dasar pergerakan kelelawar dalam satu ruang sebagai bentuk dari massa bangunan, kemudian menggunakan material penyusun ruang dengan bahan-bahan yang berasal dari habitat kelelawar serta program wisata penangkaran yang bertujuan untuk membantu Kalong sulawesi agar tidak punah dengan cara memelihara dan mengembangbiakannya.
\end{abstract}

Kata kunci: acerodon celebensys; kalong; kelelawar buah; kesehatan; persepsi buruk; polusi.

\begin{abstract}
Humans with all the advancements in science and technology, facilitate all kinds of processes in various kinds of activities. The comfort provided has had a profound impact since the days of the industrial revolution. But with all the damage, there are also many impacts caused by this development. Environmental pollution and unpredictable climate change are global problems facing the world. Some of the main causes are pollution generated from various industries and transportation. This causes disruption of environmental ecosystems and other living things. Indonesia consists of many islands with various uniqueness in it, ranging from language, culture, and living things in it. One of the living things that are threatened with extinction due to environmental changes and the actions of liar hunters are bats. Fruit bats or Flying Fox are endemic animals to Sulawesi that have various important roles in the environment behind the bad perception of humans towards these creatures. The presence of bats in plantation and forest areas can improve fruit quality because of its role as cross-pollinating agents. This bat with the Latin name Acerodon Celebensysis is only found in the Sulawesi archipelago and lives side by side with the community and has a relationship with local culture. However, the bad perception of bats that have a bad impact on health and also the hunting of liars by the community to be used as food has caused the population to decline. An approach is needed to help this endemic animal population and also increase people's insight to get to know Kalong and rectify bad perceptions about this endemic animal of Sulawesi.
\end{abstract}

Keywords: acerodon celebensys; bad perception; fruit bats; pollution; population. 


\section{PENDAHULUAN}

\section{Latar Belakang}

Terganggunya kehidupan kelelawar buah yang memegang peranan penting dalam keberlangsungan keberagaman kehidupan di dalam hutan menjadi latar belakang dilakukannya penilitan. Hal ini terjadi akibat pemburuan satwa liar yang sering dilakukan di Sulawesi dan pengaruh global yaitu perubahan iklim. Disamping itu, ancaman kepunahan hewan endemik ini berdampak langsung pada hasil pertanian yang kualitas dan jumlahnya menurun.

\section{Rumusan Permasalahan}

Persepsi buruk akan Kelelawar yang menjadi hewan pemabawa penyakit menyebabkan adanya ketidaksetaraan antara manusia, kelelawar dan makhluk hidup lainnya. Bagaimana sebuah arsitektur dapat melampaui ekologi dalam merespon permasalahan populasi kelelawar yang sudah berkurang dengan tidak mengurangi faktor spiritualitas yang ada di Sulawesi?

\section{Tujuan}

Proyek memiliki target untuk membantu mengurangi permasalahan populasi kelelawar buah yang menurun akibat pemburuan liar dan peruabhan iklim. Ancaman punah kelelawar buah ini dapat mempengaruhi spiritualitas setempat yang menganggap kelelawar buah ini sebagai hewan pelindung yang diperintahakan oleh Sultan Soppeng. Punahnya hewan ini juga berdampak pada kelangsungan kehidupan hutan.

\section{KAJIAN LITERATUR}

\section{Ekologi}

Kata "Ekologi" diciptakan oleh seorang ahli biologi Jerman pada tahun 1869 dan berasal dari kata Yunani, "Oikos" yang berarti "Rumah". Ekologi adalah cabang ilmu yang berhubungan dengan studi tentang interaksi antara organisme hidup dan fisiknya lingkungan hidup. Keduanya terkait erat dan mereka memiliki interaksi terus menerus sehingga terjadi perubahan lingkungan yang berpengaruh pada organisme hidup dan sebaliknya. (De \& De, 2009)

\section{Deep Ecology}

Menurut Bill Devail George dalam bukunya yang membahas tentang Deep Ecology mengatakan, meskipun ekologi dipandang dan diakui sebagai sebuah ilmu sains, ekologi sendiri memiliki makna universal yang lebih besar dan utama. Pengetahuan ini dapat ditinjau dari berbagai macam hal. Deep Ecology sangat konservatif dan memiliki hubungan serta wawasan yang kuat mengenai banyak kepercayaan dan filosofis tentang manusia purba. (Devall, 1985)

\section{Beyond Ecology dalam Arsitektur}

Berikut adalah beberapa unsur dari Beyond Ecology (Sutanto, 2020) :

- Energy and Emission: Mengolah dan meminimalisir hasil emisi yang dihasilkan oleh bangunan dengan penerapan desain dan penggunaan material serta organisasi ruang.

- Adaptation Architecture: Melakukan penelitian atau riset mengenai dampak yang terjadi terhadap lingkungan, seperti pengaruh perubhana iklim global dan lain-lain.

- Resilience Architecture: Kemampuan bangunan bertahan dan menghadapi masalah masalah yang akan terjadi ke depannya.

- Suistainable Digital Architecture: Mampu mengolah data-data lingkungan sekitar sebagai acuan dan strategi baru dalam menentukan sebuah ruang

- New Technology: Pemanfaatan teknologi terbaru dalam ruang, program dan material dalam bangunan. 
- Context: Kontekstual terhadap letak dan pengaruh hubungan terhadap lingkungan sekitar dimana sebuah spasial ditempatkan.

\section{Perubahan Iklim}

Masalah global yang sedang dihadapi manusia adalah perubahan iklim yang mempengaruhi banyak aspek kehidupan yang ada di bumi. Dampak yang dimiliki tidak hanya berpengaruh pada manusia saja, namun juga makhluk hidup serta lingkungannya. Perubahan iklim merupakan salah satu bentuk dari global warming yang sedang terjadi. (De \& De, 2009)

Meningkatnya pembakaran bahan bakar fosil dan penyalahgunaan lahan terus menyumbang peningkatan gas rumah kaca ke atmosfer bumi. Gas tersebut diantaranya adalah karbon dioksida $\left(\mathrm{CO}_{2}\right)$, metana $\left(\mathrm{CH}_{4}\right)$, dan nitrogen dioksida $\left(\mathrm{N}_{2} \mathrm{O}\right)$. Karakteristik utama dari perubahan iklim adalah meningkatnya suhu rata rata global, perubahan pergerakan awan dan curah hujan yang tidak menentu, mencairnya lapisan es dan salju, meningkatnya suhu laut dan tingkat keasamannya dimana mempengaruhi penyerapan panas dan karbon dioksida $\left(\mathrm{CO}_{2}\right)$ dari atmosfer. (De \& De, 2009)

\section{Persepsi Spasial}

Melihat dari sudut pandang umum, ruang memiliki bentuk tiga dimensi serta mampu ditempati oleh bagian dari suatu benda. Dalam ilmu Arsitektur, sebuah ruang menjadi bagian dari 3 dimensi dan memiliki batas berupa komponen atau elemen penyusun bawah, samping, dan juga atas sebagai pemisah keluar masuk sebuah ruang.

Sebuah bangunan dikatakan mempunyai ruang apabila ditempati ataupun juga dihuni, akan memberikan sebuah hubungan timbal balik antara ruangan tersebut terhadap penggunananya. Dalam hubungan manusia dan Arsitektur, manusia memegang paling banyak hubungan dengan ruang. Hal ini dikarenakan manusia memiliki cipta rasa serta karsa di dalamnya. Hubungan ini terbagi menjadi dua yaitu hubungan secara fisik maupun non-fisik (psikis) ruang. (Studio, 2020)

\section{Batas Ruang}

Batas ruang umumnya terdiri dari elemen horizontal dan juga vertikal. Bentuk solid yang mudah diamati adalah bentuk kubus yang tediri dari 4 sisi. Batas horizontal dalam sebuah kubus terletak pada sisi dan sudut datar di dalamnya. Sedangkan batasan vertikal yang dapat diamati adalah bidang tempat kita berpijak dan langit - langit di dalamnya. (Studio, 2020)

\section{Kelelawar Buah}

Kelelawar menjadi satu-satunya mamalia yang memiliki kemampuan untuk dapat terbang. Keunikan lainnya yang dimiliki kelelawar adalah pola hidupnya yang nocturnal dan menghabiskan waktu istirahatnya dengan bergantungan di goa atau pepohonan.

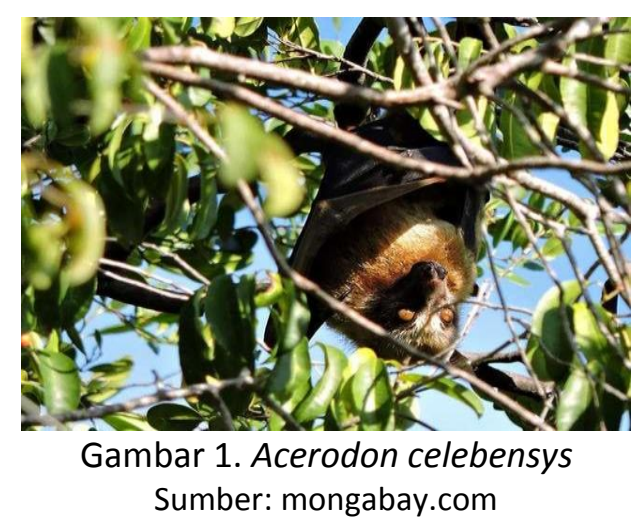


Dalam sebuah riset yang dilakukan The Journal of Experimental Biology, didapatkan pola pergerakan kelelawar yang identik dilakukan secara berulang - ulang. Pola identik yang membentuk sebuah looping ini didapatkan setelah melakukan pengujian berulang - ulang di hari yang berbeda. Bentuk looping yang dihasilkan menjadi pola pengalaman ruang yang dirasakan atau dialami oleh kelelawar tersebut. (SHEHERAZADE, 2018). Bentuk dasar dari pola tersebut nantinya akan digunakan sebagai dasar pola penyusunan massa dalam membentuk gubahan.

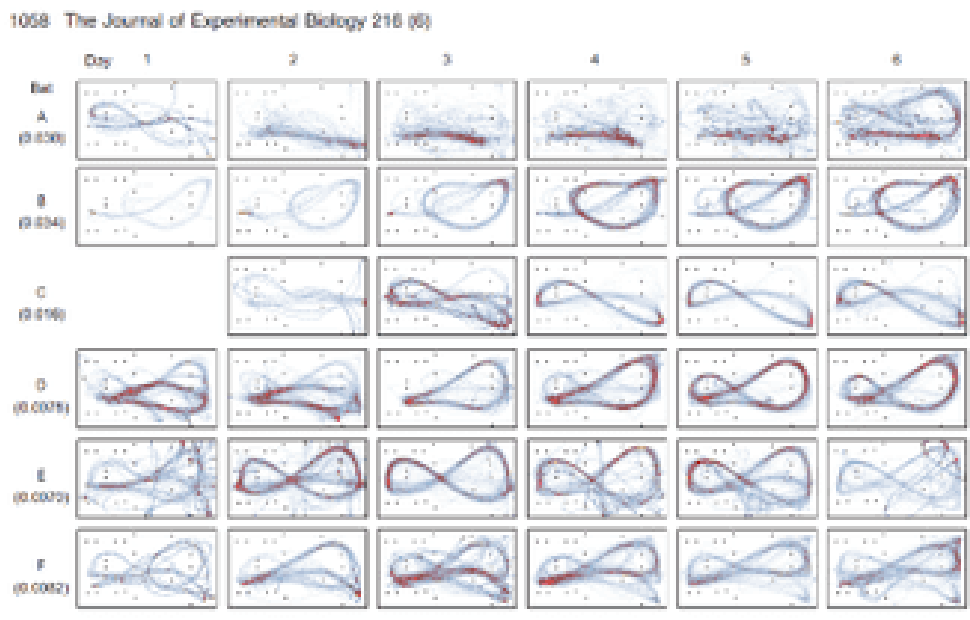

Gambar 2. Pola Gerakan Kelelawar

Sumber: (SHEHERAZADE, 2018)

Kelelawar buah sendiri memiliki peranan sebagai agen penyerbukan silang pada beberapa buah yang dihinggapinya. Hal ini menunjukan jika kelelawar memegang peranan penting dalam keberagaman dan kelangsungan tumbuh kembangnya hutan di Sulawesi. Terjadi fenomena perburuan satwa liar yang dilakukan oleh masyarakat untuk memenuhi kebutuhan pasar, yang dimana hal ini merupakan salah satu yang menyebabkan beberapa hewan liar di hutan terancam punah. (Sheherazade, Ober, \& Tsang, Contributions of bats to the local economy through durian pollination in Sulawesi, Indonesia, 2018)

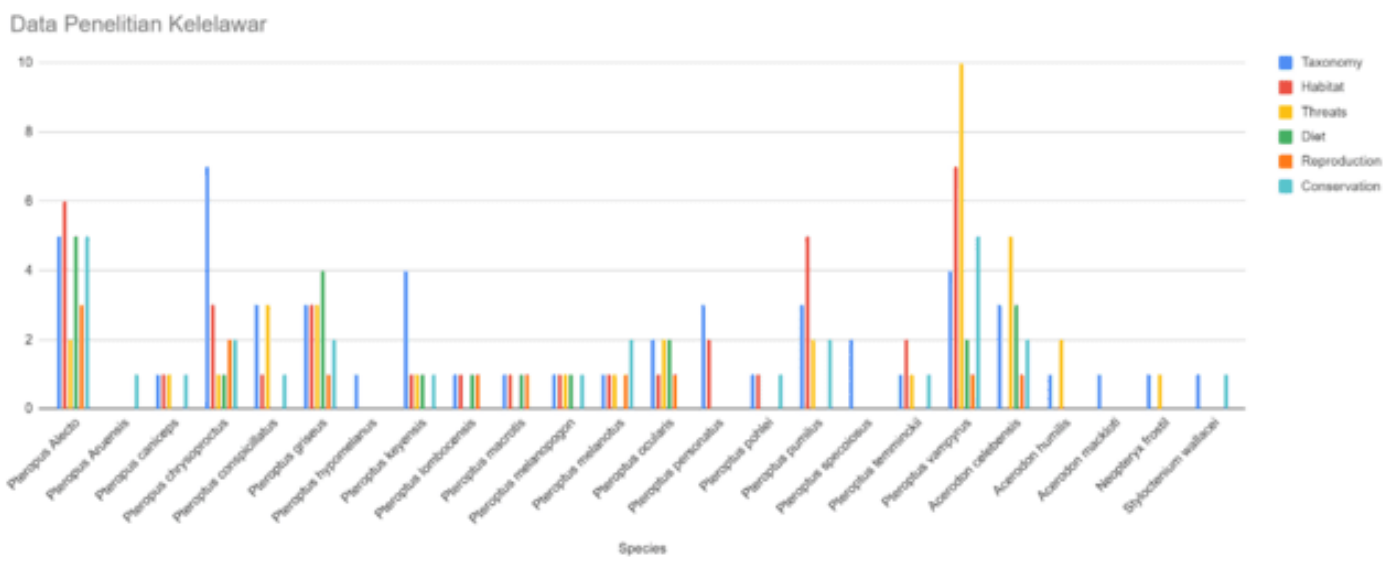

Gambar 3. Peta Perburuan Satwa liar di Sulawesi

Sumber : (Sheherazade, Yasman, Pradana, \& Tsang, 2017)

Dapat dilihat jika beberapa satwa liar masuk dalam target perburuan liar yang dilakukan dan salah satunya adalah kelelawar buah. Daging kelelawar cukup popular untuk dijadikan makanan di Sulawesi. Kelelawar buah merupakan salah satu spesies megabat yang dimana memiliki ukuran tubuh yang besar ketimbang spesies lainnya. Dapat dilihat, jika Acerodon celebensis menduduki peringkat kedua dengan ancaman punah yang tinggi dibandingkan spesies kelelawar lainnya. 


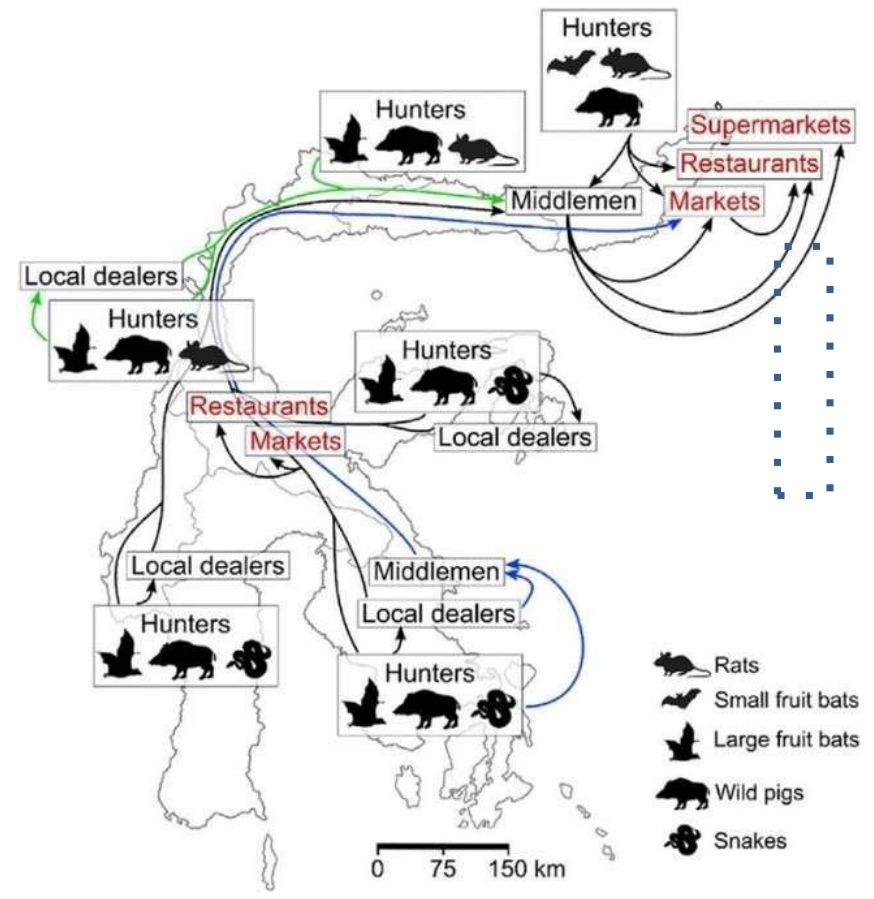

Gambar 4. Diagram Spesies Kelelawar

Sumber : (Sheherazade, Yasman, Pradana, \& Tsang, 2017)

Kelelawar buah sendiri memiliki rantai makanan yang berpengaruh pada kelangsungan dan keberagaman hidup di hutan. Kehidupan kelelawar buah sendiri terancam oleh beberapa faktor, diantaranya pengaruh global yaitu perubahan iklim dan juga faktor eksternal dari perburuan liar oleh masyarakat setempat. Salah satu komoditas buah yang terkenal adalah durian. Semenjak perburuan liar yang marak mengancam kehidupan kelelawar buah, tingkat hasil panen buah durian turut menurun. (Sheherazade, Ober, \& Tsang, Contributions of bats to the local economy through durian pollination in Sulawesi, Indonesia, 2018)

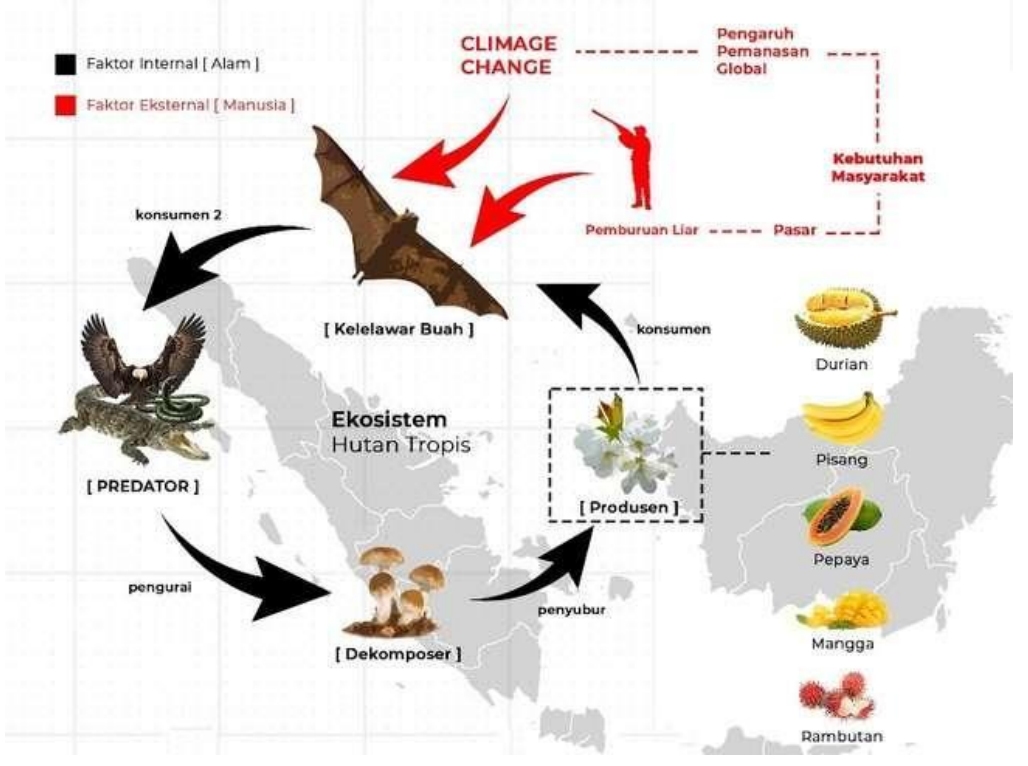

Gambar 5. Diagram Rantai Makanan

Sumber: Dokumen Pribadi, 2021 


\section{METODE}

Pengumpulan data dilakukan dengan melakukan studi pada literatur yang sudah ada dengan metode penelitian yang bersifat kualitatif. Pendekatan desain yang digunakan adalah dengan konsep Persepsi Spasial, dimana mengkaitkan pengalaman ruang yang dialami kelelawar dan manusia. Penelitian didasari dengan fenomena-fenomena yang terjadi. Strategi desain juga menerapkan konsep Beyond Ecology dan Persepsi Spasial Kelelawar dalam bangunan.

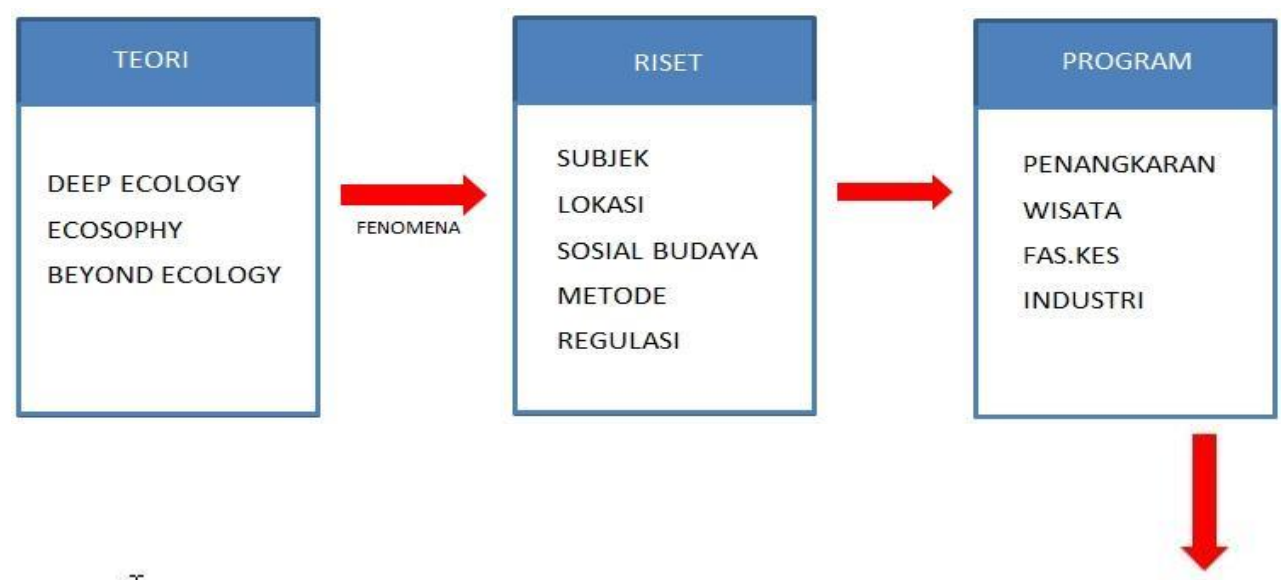

\section{PERANCANGAN}
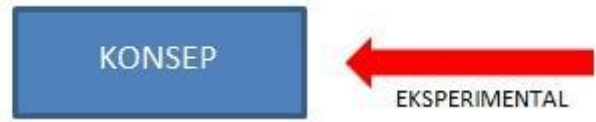

METODE DESAIN

Gambar 6. Kerangka Berfikir

Sumber: Dokumen Pribadi, 2021

Dari pengumpulan data yang digunakan, untuk menyampaikan pentingnya kehidupan kelelawar ke dalam persepsi manusia dilakukan dengan cara pemanfaatan persepsi spasial yaitu dengan manipulasi elemen-elemen pembentuk ruang dalam arsitektur. Pemilihan pengggunaan material dan pola penyusunan ruang yang dirancang berdasarkan kehidupan kelelawar, seperti penggunaan material dengan tekstur batu dan kayu untuk mencirikan habitat kelelawar buah yang hidup di goa dan pepohonan.

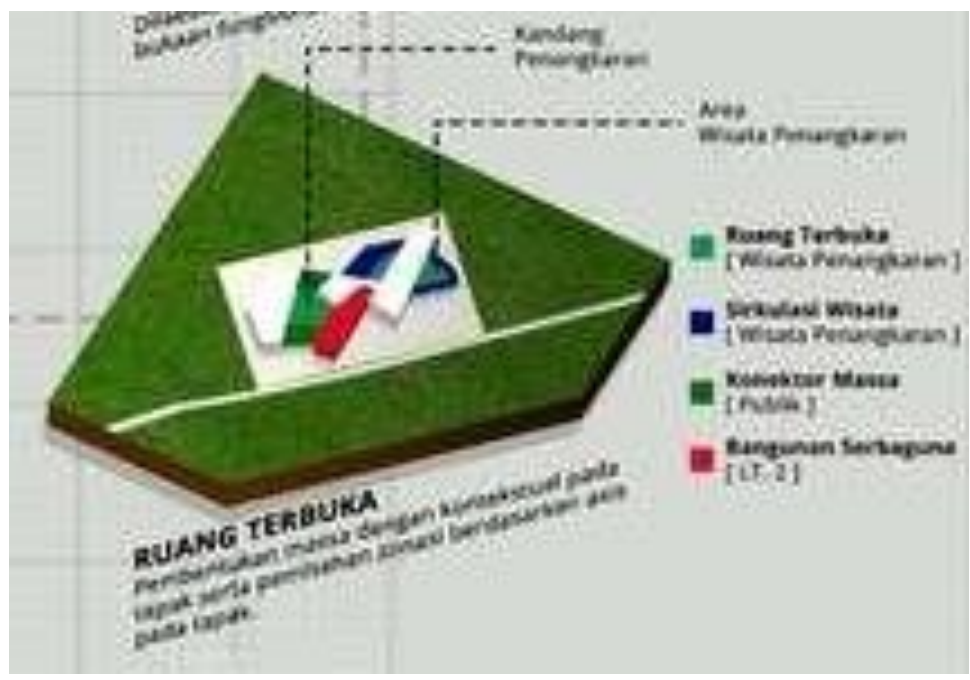

Gambar 7. Tahapan akhir Gubahan Massa

Sumber: Dokumen Pribadi, 2021 
Penerapan pola sirkulasi looping didasari pada pola yang dihasilkan kelelawar dalam sebuah jurnal penelitian yang mengamati kehidupan kelelawar (SHEHERAZADE, 2018). Pengujian ini dilakukan beberapa kali dan menghasilkan bentuk sirkulasi yang serupa. Dari pola pada Gambar 2, dilakukan impose dan penyesuaian terhadap kontekstual tapak untuk menghasilkan sebuah dasar gubahan massa.

Berikut adalah beberapa konsep yang diterapkan dalam program dan perancangan bangunan : - LOOPING

Menerapkan pola looping sebagai bentuk sirkulasi mendasar dalam bangunan yang kemudian dikembangkan menjadi bentuk masa dengan organisasi ruang sesuai dengan fungsi bangunan.

- UPSIDEDOWN

Menggunakan program pameran tematik untuk menerapkan persepsi spasial kelelawar yang menghabiskan waktunya dengan bergantungan. Penerapannya dalam ruang, berupa instalasi terbalik dalam sebuah ruangan memanjang agar pengguna dapat merasakan pengalaman upsidedown.

\section{- ECHOLOCATION}

Menerapkan area pameran ECHOLOCATION berupa teknologi virtual reality untuk mendapatkan pengalaman ruang yang lebih nyata dan interaktif.

- TECHNOSPHERE

Penerapan TECHNOSPHERE berupa teknologi yang digunakan dalam program. Teknologi berupa VR pada beberapa program kegiatan di dalam bangunan.

\section{DISKUSI DAN HASIL}

\section{Diskusi}

Kelelawar dikenal oleh masyarakat umum sebagai makhluk hidup yang membawa dampak negatif dalam kehidupan manusia. Namun pada hakikatnya, semua makhluk hidup memiliki peranan masing-masing dalam menjaga kehidupan satu dengan yang lainnya. Penyetaraan pandangan antara manusia dengan kelelawar dibutuhkan untuk saling menghargai satu dengan yang lainnya. Fenomena perburuan liar yang mengancam kepunahan spesies ini didasari oleh ketidaksadaraan manusia akan pentingnya kelelawar bagi kelangsungan dan keberagaman kehidupan di dalam hutan. Penyampaian informasi tentang pentingnya kehidupan kelelawar perlu dilakukan dengan mudah. Oleh karena itu, penggunaan metode persepsi spasial dipilih sebagai metode perancangan desain bangunan.

Metode ini menerapkan beberapa aspek habitat kelelawar seperti meniru penggunaan material dalam penyusunan elemen ruang dalam area wisata dengan tekstur batu dan kayu untuk mencirikan karakteristik habitat kelelewar. Selain itu penerapan teknologi dalam area wisata juga digunakan untuk mencapai aspek beyond ecology.

\section{Hasil}

Dengan menggunakan konsep persepsi spasial dan transformasi massa yang menerapkan bentuk dasar looping, didapatkan sebuah bentuk massa dengan ruang terbuka di bagian tengah dimanfaatkan sebagai area wisata penangkaran. Bangunan memiliki fungsi sebagai tempat perawatan dan pengembangbiakan kelelawar buah, sebelum nantinya dilepaskan kembali ke habitat aslinya (hutan tropis). 


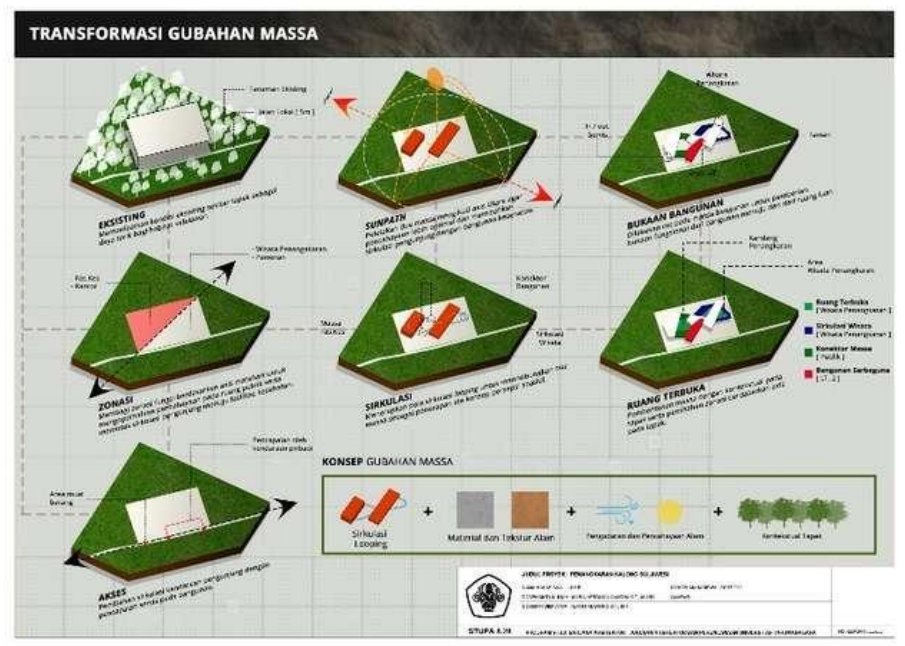

Gambar 8. Proses Desain

Sumber: Dokumen Pribadi, 2021

Area zona berwarna hijau merupakan area penangkaran yang menjadi area wisata dalam program bangunan. Kelelawar yang berada di area tersebut, merupakan kelelawar yang sudah sehat dan siap untuk dilepaskan kembali menuju habitat aslinya. Material yang digunakan dalam bangunan menggunakan material yang berkaitan erat dengan habitat kelelawar yaitu, batu dan kayu. Material tersebut bertujuan menyampaikan informasi mengenai habitat kelelawar kepada pengunjung dan juga untuk lebih menyatu dengan lingkungan sekitarnya.

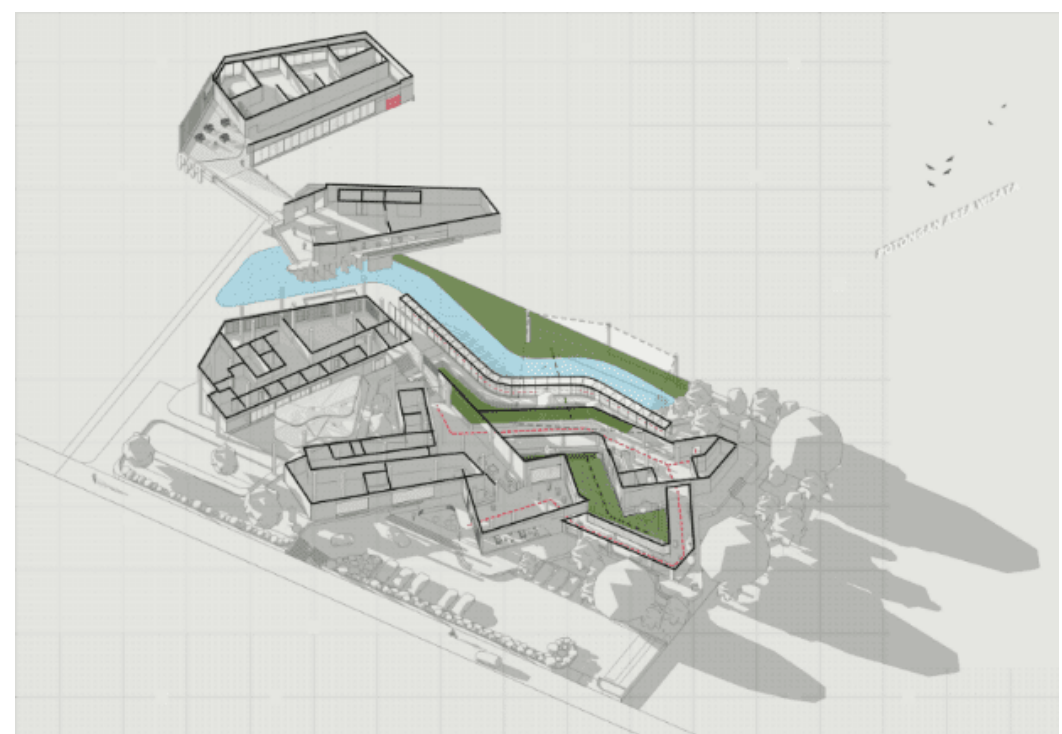

Gambar 9. Diagram Aksonometri Denah Bangunan

Sumber: Dokumen Pribadi, 2021

Selain material bangunan, program galeri informasi dan juga pameran VR bertujuan untuk memberikan informasi mengenai kehidupan kelelawar dan peranan penting yang dimilikinya dalam menjaga kelangsungan dan keberagaman hidup hutan tropis di Indonesia. Pameran VR berupa visualisasi spasial yang terbentuk dari silhouete cahaya, memberikan gambaran kelelawar dalam menereka ruangan disekitarnya dengan bantuan gelombang cahaya. Dalam hal ini menerapkan prinsip yang sama namun dengan menggunakan stimulus yang berbeda dalam menggambarkan spasial. 


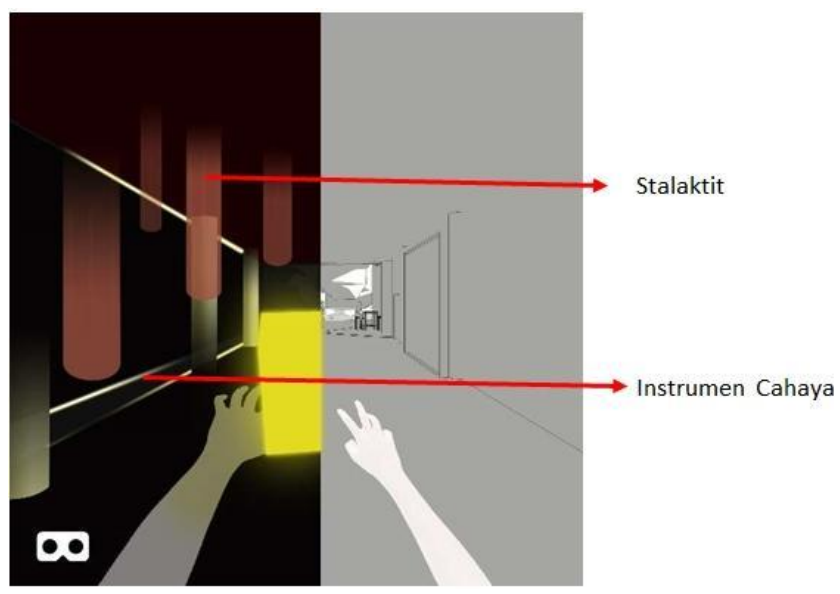

Gambar 10. Ilustrasi Simulasi VR Echolocation Sumber: Dokumen Pribadi, 2021

Metode penangkaran menggunakan kandang sebagai media habitat bagi kelelawar. Pengadaan kelelawar ke dalam bangunan dapat dilakukan dengan beberapa cara menurut Peraturan Menteri Kehutanan No. P.19/ Menhut-II / 2005 tentang Penangkaran Tumbuhan dan Satwa Liar, yaitu pengadaan dengan cara penangkapan, pemberian dari masyarakat setempat, rampasan, luar negeri, maupun berasal dari lembaga konservasi.
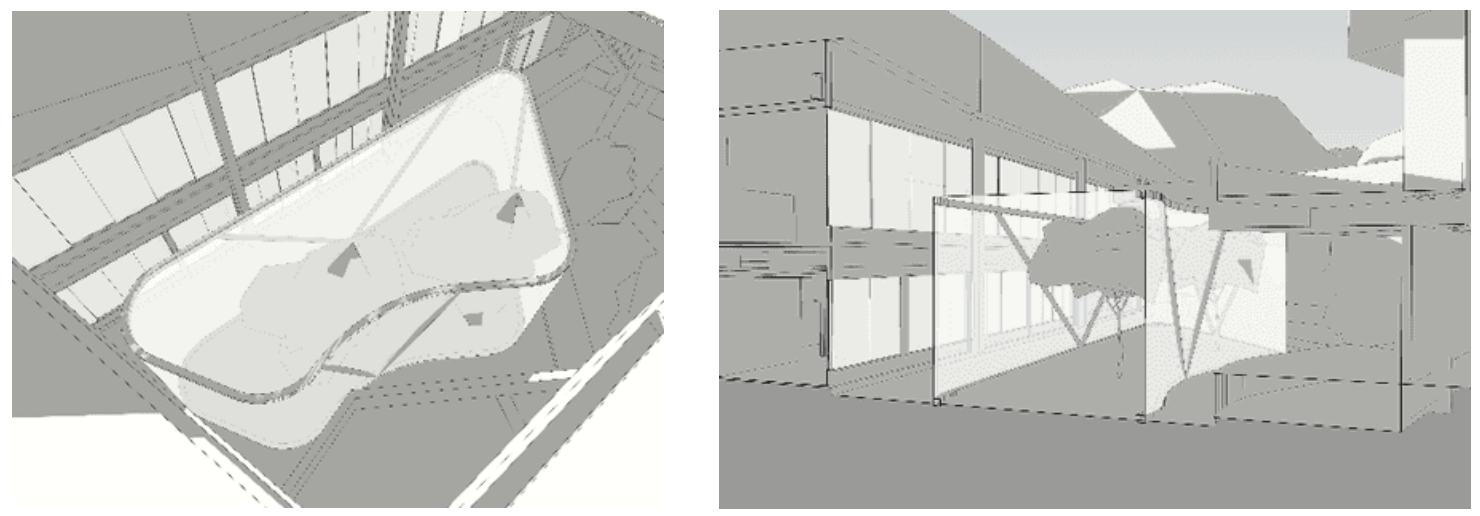

Gambar 11. Model Kandang Penangkaran

Sumber: Dokumen Pribadi, 2021

Kandang digunakan sebagai media untuk pengembangbiakan dan perawatan kelelawar sebelum nantinya akan dilepaskan kembali ke alam. Kandang berada di tengah bangunan untuk memudahkan pemantauan dan mobilisasi satwa jika dibutuhkan perawatan. Material kandang menggunakan struktur baja dengan pelapis jaring kawat untuk memudahkan kelelawar bergelantungan dan bergerak saat tidak terbang. Tapak bangunan berada di area hijau dengan lingkungan sekitar berupa hutan dan perkebunan masyarakat sekitar. Lokasi dipilih berdasarkan analisa lingkungan sekitar yang merupakan area yang dikunjungi oleh kelelawar untuk beristirahat maupun juga sebagai sumber makanan. 


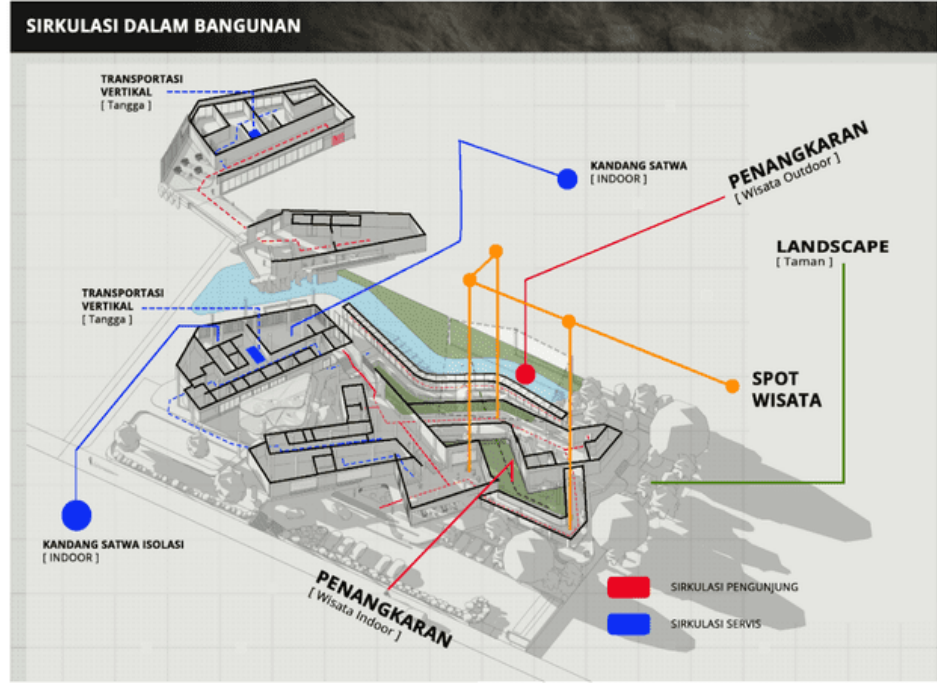

Gambar 12. Model Kandang Penangkaran

Sumber: Dokumen Pribadi, 2021

\section{KESIMPULAN DAN SARAN}

\section{Kesimpulan}

Pendekatan psikologi dilakukan dengan menggunakan pengalaman ruang dengan tujuan untuk memberikan pengaruh pada persepsi alam sadar manusia yang bertujuan untuk melihat makhluk hidup lain hanya sebatas kehadirannya saja. Dibalik kehadirannya di muka bumi ini, ada hal lain yang dimilikinya terlepas dari penilaian manusia yang baik dan juga buruk. Kelelawar yang memiliki pernanan penting dalam keberlangsungan hutan tropis, dan beberapa penyerbukan pada buah tertentu tentunya akan membawa pengaruh besar jika sampai punah. Terlebih, kelelawar dengan nama latin Acerodon celebensis ini merupakan hewan endemik yang hanya berada di kepulauan Sulawesi.

\section{Saran}

Perlunya data yang lebih luas lagi mengenai kehidupan kelelawar untuk dijadikan sumber, dan landasan agar nantinya dapat dikembangkan dan dimplementasikan dalam skala yang lebih besar. Perburuan liar akan terus terjadi jika tidak adanya gerakan untuk mencegah. Penyuluhan dan juga rehabilitasi satwa liar yang terancam punah dirasa diperlukan dalam hal ini.

\section{REFERENSI}

Arjunari, F., S.Si.,M.Si, D. I., \& Maiser Syaputra. (2018). IDENTIFIKASI JENIS DAN KARAKTERISTIK HABITAT KELELAWAR DI GUA.

De, A. K., \& De, A. K. (2009). Environment And Ecology. West Bengal: New Age International.

Devall, B. (1985). Deep Ecology. Layton, Utah 8401: Gibbs M. Smith, Inc.

Ranasaleleh, T. A., Maheswari, R. A., Sugita, P., \& Manulu, W. (2013). Identifikasi Kelelawar Pemakan Buah Asal Sulawesi Berdasarkan Morfometri.

Sheherazade. (2018). Ecosystem Services of Pteropodid Bats. with Special Attention To Flying Foxes (Pteropus And Acerodon) In Sulawesi, Indonesia.

Sheherazade, Ober, H. K., \& Tsang, S. M. (2018). Contributions of bats to the local economy through durian pollination in Sulawesi, Indonesia.

Sheherazade, Yasman, Pradana, D. H., \& Tsang, S. M. (2017). The role of fruit bats in plant community changes in an urban forest in Indonesia.

Studio, A. (2020). Pengertian dan Organisasi Ruang dalam Arsitektur. Retrieved from Arsitur Studio: https://www.arsitur.com/2017/11/pengertian-dan-organisasi-ruangdalam.html 